\title{
Viabilidade de cepas de Malassezia pachydermatis mantidas em diferentes métodos de conservação
}

\author{
Viability of Malassezia pachydermatis strains maintained \\ in various storage mediums
}

\author{
Marília Dutra Girão ${ }^{1}$, Marilena Ribeiro do Prado ${ }^{1}$, Raimunda Sâmia Nogueira Brilhante ${ }^{1,2}$, \\ Rossana Aguiar Cordeiro ${ }^{2}$, André Jalles Monteiro ${ }^{3}$, José Júlio Costa Sidrim ${ }^{2}$ \\ e Marcos Fábio Gadelha Rocha ${ }^{1,2}$
}

\begin{abstract}
RESUM0
Amanutenção de culturas de Malassezia pachydermatis em micotecas éimportante para estudos retrospectivos e prospectivos. O objetivo deste trabalho foi avaliar o comportamento de Malassezia pachydermatis frentea diferentes métodos de conservação de culturas. Para tanto, após o processo de identificação, essa levedura foi estocada, por seis e nove meses, em salina e salina com óleo mineral a $28^{\circ} \mathrm{C}$, bem como, em ágar Dixon, ágar Dixon acrescido de glicerol e ágar Dixon acrescido de dimetil-sulfóxido (DMSO) a $-20^{\circ} \mathrm{C}$. Os meios de Dixon e Dixon acrescido de glicerol foram os métodos mais adequados ( $\mathrm{p}<$ $0,05)$ para manter a viabilidade das cepas, em seis e nove meses de estoque. Qualquer dos métodos utilizados foi conveniente para manutenção da positividade na prova da urease em seis meses de estocagem, sendo 0 ágar Dixon e 0 ágar Dixon acrescido de glicerol, os melhores $(\mathrm{p}<0,05)$ para nove meses. Portanto, para a recuperação emanutenção das características de Malassezia pachydermatis, recomenda-se o emprego do meio de Dixon ou do meio de Dixon acrescido de glicerol.
\end{abstract}

Palavras-chaves: Leveduras. Malassezia pachydermatis. Manutenção de fungos. Micoteca. Viabilidade biológica.

\begin{abstract}
The maintenance of Malassezia pachydermatis in fungal collections is very important for retrospective and prospective studies. The aim of this study was to evaluate the behavior of Malassezia pachydermatis in different storage methods. After the identification process, M. pachydermatis strains were stored for six and nine months, in saline and saline plus mineral oil at $28^{\circ} \mathrm{C}$, as well as in Dixon's agar, Dixon's agar plus glycerol and Dixon's agar plus dimethyl-sulfoxide (DMSO), at $-20^{\circ} \mathrm{C}$. Dixon's agar and Dixon's agar plus glycerol were the most adequate methods $(\mathrm{p}<0.05)$ for the maintenance of Malassezia pachydermatis viability, after six and nine months of storage. All the methods used were capable of maintaining the urease activity at six months of storage, but only Dixon's agar and Dixon's agar plus glycerol were statistically adequate at nine months $(\mathrm{p}<0.05)$. Thus, to assure Malassezia pachydermatis recovery and to maintain its characteristics, Dixon's agar or Dixon's agar plus glycerol should be used.
\end{abstract}

Key-words: Yeast. Malassezia pachydermatis. Fungi maintenance. Biological viability.

0 gênero Malassezia compreende leveduras lipofilicas que fazem parte da microbiota cutânea do homem e animais. 0 seu isolamento a partir do meio ambiente é excepcional, pois sua sobrevivência está condicionada à presença de uma fonte lipídica, excetuando-se a espécie Malassezia pachydermatis, que é menos exigente no requerimento de lipídeos para seu desenvolvimento 151625 .

A partir da década de 1980, as leveduras do gênero Malassezia ganharam especial atenção, principalmente na medicina humana, em virtude das formas recidivantes de

1. Faculdade de Veterinária do Programa de Pós-graduação em Ciências Veterinárias da Universidade Estadual do Ceará, Fortaleza, CE, Brasil. 2. Departamento de Patologia e Medicina Legal da Faculdade de Medicina do Centro Especializado em Micologia Médica da Universidade Federal do Ceará, Fortaleza, CE, Brasil. 3. Departamento de Estatística e Matemática Aplicada da Universidade Federal do Ceará, Fortaleza, CE, Brasil.

Endereço para correspondência: Dra. Marília Dutra Girão. R. Rodriques Júnior 712, Centro, 60060-000 Fortaleza, CE, Brasil.

Tel: 85 9946-1540, Fax: 85 295-1736

e-mail: mariliagirao@ hotmail.com

Recebido para publicação em 11/11/2003

Aceito em 19/4/2004 
dermatites seborréicas em indivíduos imunossuprimidos e das fungemias em neonatos prematuros submetidos à alimentação parenteral ${ }^{19} 25$.

Por décadas, o gênero Malassezia foi limitado a duas espécies, sendo uma lipodependente e outra não, representadas pela M. furfur e M pachydermatis, respectivamente ${ }^{18}$. Em 1996, estudos genotípicos de diversas cepas, associados a características fenotípicas, permitiram a identificação de sete espécies distintas, denominadas: M. furfur, M. pachydermatis, M. sympodialis, M. slooffiae, M. restricta, M. globosa e M obtusa ${ }^{15}$.

M. pachydermatis é a espécie mais adaptada a animais, sendo freqüentemente isolada como microbiota de conduto auditivo e pelame de cães, gatos e outras espécies de animais domésticos e selvagens. Em cães tem sido comumente associada a quadros clínicos de otites externas e dermatites, estando sua proliferação intensa associada a processos de desequilíbrio local ou sistêmico ${ }^{16} 2022$.

A manutenção de microrganismos em micotecas é de fundamental importância para estudos retrospectivos e prospectivos, que enfoquem sua biologia, etiologia e aspectos epidemiológicos. Entretanto, para uma satisfatória análise fenotípica e genotípica, a longo prazo, é necessária a escolha adequada do método de preservaçãa $0^{5}$.

A seleção de métodos apropriados para estocagem de fungos baseia-se nas características fenotípicas inerentes a cada microrganismo, bem como, no comportamento de cada espécie frente aos métodos de preservação. Diversas técnicas de estocagem têm sido relatadas na literatura especializada, porém, nenhuma tem se mostrado plenamente eficaz, requerendo-se a conjunção de dois ou mais métodos, para garantir melhor recuperação das cepas² 351021 .

0 objetivo deste trabalho foi avaliar o comportamento de cultivos de M pachydermatis, procedentes de condutos auditivos de cães, frente a diferentes métodos de estocagem.

\section{MATERIAL E MÉTODOS}

Colheita do espécime clínico. Os espécimes clínicos foram obtidos através de dois swabs estéreis introduzidos, com movimentos rotatórios, no terço proximal do conduto auditivo dos cães, conforme citado por Machado et al ${ }^{22}$. Este procedimento foi realizado após o preenchimento de um questionário com dados referentes ao animal, como: estado de higidez, idade, sexo, raça, pelagem, habitat, conformação da orelha e possíveis utilizações de medicamentos.

Processamento laboratorial. Para a execução do exame direto eram confeccionados esfregaços do material biológico, corados pela técnica de Gram, sendo realizada a leitura em 40 campos, com aumento de 40 vezes.

0 material clínico presente no segundo swab foi semeado nos meios de cultura ágar Sabouraud dextrose, ágar Sabouraud dextrose acrescido de cloranfenicol $(0,05 \mathrm{~g} / \mathrm{l})$, ágar Sabouraud dextrose com cloranfenicol $(0,05 \mathrm{~g} / \mathrm{l})$ e cicloheximida $(0,5 \mathrm{~g} / \mathrm{l})$ e meio de Dixon, para 0 isolamento primário. A partir de então, foram realizadas observações diárias, por um período de dez dias, conforme recomendado por Sidrim e Moreira ${ }^{25}$.

As análises macro e micro morfológicas basearam-se na metodologia preconizada por Sidrim e Moreira ${ }^{25}$. As estruturas microscópicas sugestivas de Malassezia spp, analisadas pela coloração de Gram, apresentavam-se como células ovaladas com brotamento em colarete. Quanto à macromorfologia, as colônias mostravam-se com textura glabrosa e coloração variando no tom de amarelo-creme.

As leveduras sugestivas de Malassezia spp eram consideradas como M pachydermatis, quando apresentavam crescimento concomitante no ágar Sabouraud dextrose e no meio de Dixon, associado à positividade na prova da urease, conforme descrito por Sidrim e Moreira ${ }^{25}$.

Estoque das cepas. Os métodos utilizados consistiram de: 1) salina; 2) salina com óleo mineral ( $1: 10)$; 3) ágar Dixon; 4) ágar Dixon acrescido de glicerol a 10\% (crioprotetor); 5) ágar Dixon acrescido de dimetil-sulfóxido 10\% (DMSO; crioprotetor). Nos dois primeiros métodos, os cultivos eram mantidos à temperatura ambiente $\left(28^{\circ} \mathrm{C}\right)$, enquanto que os demais foram submetidos a congelamento a $-20^{\circ} \mathrm{C}$.

Verificação da viabilidade das cepas. Após seis meses de estocagem, as 48 cepas de $\mathrm{M}$ pachydermatis mantidas a $-20^{\circ} \mathrm{C}$, em ágar Dixon, ágar Dixon acrescido de glicerol 10\% e ágar Dixon com DMSO 10\%, foram descongeladas. Em seguida, um pequeno inóculo foi repicado para ágar Dixon, sendo observado diariamente por um período de dez dias. Nas cepas estocadas em salina e salina com óleo mineral, a $28^{\circ} \mathrm{C}$, após leve agitação, uma pequena alíquota foi transferida para 0 meio Dixon, onde 0 crescimento foi também acompanhado por 10 dias. As cepas de M. pachydermatis que cresceram no ágar Dixon foram repicadas em ágar Sabouraud dextrose, com o objetivo de se avaliar a preservação da não lipo-dependência. A prova da urease foi realizada com 0 objetivo de se verificar a manutenção da atividade desta enzima. Após nove meses de estoque, as condutas supracitadas foram repetidas, no entanto, com somente 24 cepas de M pachydermatis, em virtude de razões técnico-operacionais.

Análise estatística. Na análise dos dados foram utilizados testes de homogeneidade de proporções (Teste exato de Fisher) ${ }^{14}$. Os valores de $p \leq 0,05$ foram considerados significantes.

\section{RESULTAD0S}

Os resultados de seis meses de manutenção demostraram que houve recuperação estatisticamente significante das cepas de $\mathrm{M}$. pachydermatis estocadas em ágar Dixon a $-20^{\circ} \mathrm{C}$ $(70,8 \% ; n=34)$, em ágar Dixon acrescido de glicerol $(68,8 \% ; n=33)$, em ágar Dixon acrescido de DMSO (68,8\%; $\mathrm{n}=33)$ e em salina com óleo mineral $(60,4 \% ; \mathrm{n}=29)$, em relação ao emprego da salina (39,6\%; $\mathrm{n}=19)$ (Figura 1).

Quando utilizou-se o ágar Sabouraud visando avaliar a manutenção da não-lipodependência das cepas de M. pachydermatis recuperadas em ágar Dixon, a 


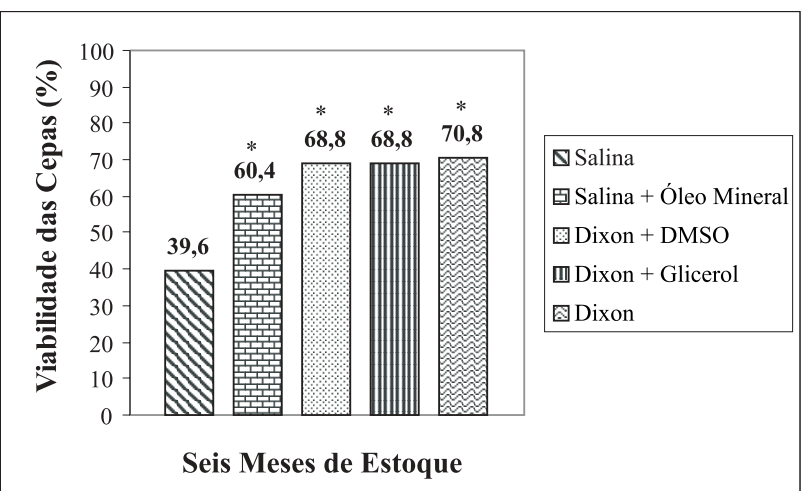

Ficura 1 - Viabilidade de cepas de M. pachydermatis mantidas em diferentes métodos de estocagem, por período de seis meses.

$* p<0,05=$ valores estatisticamente significantes.

* Salina + Óleo Mineral, Dixon + DMSO, Dixon + Glicerol e Dixon > Salina.

partir da manutenção de seis meses, evidenciou-se que 100,$0 ; 82,8 ; 82,4 ; 81,8$ e 78,8\% das cepas mantidas, respectivamente, em salina, salina com óleo mineral, ágar Dixon, ágar Dixon acrescido de DMSO e ágar Dixon acrescido de glicerol, cresceram independentemente do método de conservação adotado ( Tabela 1).

Tabela 1 - Uso de ágar Sabouraud dextrose para avaliação da manutenção de nãolipodependência e da atividade de urease em cepas de M. pachydermatis estocadas por períodos de seis e nove meses.

\begin{tabular}{|c|c|c|c|c|c|c|c|c|}
\hline \multirow{4}{*}{ Métodos de estoque } & \multicolumn{8}{|c|}{ Tempo de conservação } \\
\hline & \multicolumn{4}{|c|}{ seis meses } & \multicolumn{4}{|c|}{ nove meses } \\
\hline & \multicolumn{2}{|c|}{ ágar Sabouraud } & \multicolumn{2}{|c|}{ urease } & \multicolumn{2}{|c|}{ ágar Sabouraud } & \multicolumn{2}{|c|}{ urease } \\
\hline & $\mathrm{n}^{0}$ & $\%$ & $\overline{\mathrm{n}^{0}}$ & $\%$ & $\mathrm{n}^{0}$ & $\%$ & $\mathrm{n}^{0}$ & $\%$ \\
\hline Salina & 19 & 100,0 & 14 & 73,7 & 2 & 100,0 & 0 & 0,0 \\
\hline Salina + óleo mineral & 24 & 82,8 & 15 & 62,5 & 8 & 100,0 & 2 & 20,0 \\
\hline Dixon & 28 & 82,4 & 14 & 50,0 & 14 & 82,4 & 8 & $35,3^{*}$ \\
\hline Dixon + DMSO & 27 & 81,8 & 13 & 48,2 & 6 & 66,7 & 0 & 0,0 \\
\hline Dixon + glicerol & 26 & 78,8 & 13 & 50,0 & 15 & 100,0 & 9 & 60,0 \\
\hline
\end{tabular}

$* p<0,05=$ valores estatisticamente significantes

* Dixon e Dixon + glicerol > salina, salina + óleo mineral e Dixon + DMSO

Quanto à atividade de urease das cepas de M pachydermatis que cresceram em ágar Sabouraud, após seis meses de manutenção, evidenciou-se que o melhor resultado, embora sem diferença estatística em relação aos demais métodos de conservação, foi obtido com as cepas estocadas em salina ( 73,7\% de cepas positivas), sendo seguido por salina com óleo mineral (62,5\%), ágar Dixon (50\%), ágar Dixon acrescido de glicerol (50,0\%) e ágar Dixon acrescido de DMSO (48,2\%) (Tabela 1).

As 24 cepas de M. pachydermatis, após nove meses de estocagem, apresentaram melhor recuperação $(p<0,05)$ quando preservadas em ágar Dixon $(70,8 \% ; n=17)$ e em ágar Dixon acrescido de glicerol $(65,5 \% ; \mathrm{n}=15)$. Os menores índices de recuperação foram observados nas cepas mantidas em salina com óleo mineral (41,7\%; $\mathrm{n}=10)$, em ágar Dixon acrescido de DMSO $(37,5 ; \mathrm{n}=9)$ e em salina ( $8,4 \% ; n=2)$ (Figura 2$)$.



Figura 2 - Viabilidade de cepas de M. pachydermatis mantidas em diferentes métodos de estocagem, por período de nove meses.

$* p<0,05=$ valores estatisticamente significantes

$*$ Dixon + Glicerol e Dixon $>$ Salina

No em momento que utilizou-se 0 ágar Sabouraud dextrose com a finalidade se avaliar a não-lipodependência das cepas de M pachydermatis, recuperadas em ágar Dixon, a partir da manutenção de nove meses, evidenciou-se que as duas cepas $(100 \%)$ oriundas da salina, 8 (100\%) recuperadas da salina com óleo mineral, 14 ( 82,4\%) procedentes do meio de Dixon, $6(66,7 \%)$ mantidas no meio Dixon acrescido de DMSO e 15 cepas (100\%) oriundas do meio Dixon acrescido de glicerol apresentaram crescimento (Tabela 1).

A atividade de urease, após nove meses de estoque, foi avaliada nas cepas de M. pachydermatis que cresceram em ágar Sabouraud dextrose, sendo evidenciado que os resultados mais satisfatórios $(p<0,05)$ foram obtidos nas cepas estocadas em ágar Dixon acrescido de glicerol e em ágar Dixon, com 60,0 e $35,3 \%$ de positividade, respectivamente. Vale ressaltar que nenhuma cepa de $\mathrm{M}$. pachydermatis preservada em ágar Dixon com DMSO e em salina, teve esta característica bioquímica mantida ( Tabela 1).

\section{DISCUSSÃ0}

Diversos métodos vêm sendo empregados para preservação de fungos, porém, em virtude da biodiversidade destes microrganismos, não existe uma técnica padrão que seja capaz de preservá-los de forma adequada e generalizada ${ }^{2} 6212324$. Portanto, na escolha de um método para preservação de um determinado grupamento de fungos, deve ser levada em consideração a capacidade de manutenção das características fenotípicas, genotípicas e patogênicas das cepas estocadas ${ }^{5}$. Em relação às leveduras, especialmente no gênero Malassezia, sua baixa viabilidade, in vitro, constitui a principal dificuldade para estudos retrospectivos e prospectivos ${ }^{4} 10{ }^{13}$.

Neste estudo, os procedimentos realizados para investigar a manutenção da propriedade de não-lipodependência das cepas de M. pachydermatis evidenciaram que mais de 78,8 e $66,7 \%$ das cepas após seis e nove meses de estoque, respectivamente, conseguiram manter sua característica de crescer em meio sem adição de lipídeos (ágar Sabouraud), independente do método de conservação adotado. 
Vale salientar que as cepas de M pachydermatis que não cresceram em Sabouraud, após à estocagem, muito provavelmente devem ter perdido sua capacidade de crescer, independente da presença de lipídeos, em virtude da quebra da homeostase resultante das condições de conservação. Corroborando esta hipótese, Crespo et a ${ }^{10}{ }^{10}$ reportaram que 0 gênero Malassezia é muito sensível às condições in vitro.

Alguns pesquisadores encontraram cepas de Malassezia pachydermatis difíceis de se manter em ágar Sabouraud sem suplementação lipídica ${ }^{1}$. Duarte et a ${ }^{12}$ também isolaram uma cepa de M. pachydermatis que, provavelmente, tratava-se de uma variante lipo-dependente, uma vez que só evidenciava adequado desenvolvimento em meio de Dixon ou em mycosel suplementado com azeite de oliva. Portanto, na presente investigação, 0 procedimento de subcultivo no ágar Sabouraud, antes da estocagem, foi importante para evidenciar que todas as cepas de M. pachydermatis isoladas eram não-lipodependentes, sendo esta característica verificada na maioria das cepas de $\mathrm{M}$ pachydermatis estudadas em diversas partes do mundo 4911 20. Ademais, 0 cultivo no ágar Sabouraud dextrose foi importante para enfatizar a ausência das outras espécies de Malassezia, que são todas lipodependentes ${ }^{15}$.

Em relação às cepas estocadas à temperatura ambiente, a escolha da preservação em salina e salina com óleo mineral ao invés da técnica de Castellani (água destilada), deveu-se principalmente ao fato que, embora este método seja efetivo e utilizado para grande variedade de fungos 67824 , é referido como ineficaz para o gênero Malassezia ${ }^{10}$. Além disso, a solução salina em relação à água destilada, oferece melhor equilíbrio osmótico do meio. 0 presente estudo evidenciou que embora a técnica de estocagem em salina seja pouco onerosa e de fácil execução para preservação de microrganismos, não se mostrou eficaz na manutenção de cepas de $\mathrm{M}$ pachydermatis, conforme se observa com os índices de recuperação de 39,6 e 8,4\% das cepas estocadas há seis e nove meses, respectivamente (Figuras $1 \mathrm{e}$ 2). Vale salientar que o uso de óleo mineral com salina melhorou a viabilidade das cepas, em ambos os períodos de estoque (Figuras 1 e 2), provavelmente devido à sua capacidade em prevenir a desidratação do meio e diminuir a atividade metabólica do fungo estocado ${ }^{5}$; assim como em virtude da lipofilia da M. pachydermatis ${ }^{17}$.

Nas cepas de M pachydermatis estocadas, há seis meses, em ágar Dixon, em ágar Dixon acrescido de glicerol e em ágar Dixon acrescido de DMSO, a - $20^{\circ} \mathrm{C}$, observou-se que não houve diferença significativa na viabilidade das cepas estocadas com ou sem crioprotetores. Esta evidência diverge de outros achados que mostram que algumas espécies de Malassezia são sensíveis ao congelamento sem essas substâncias ${ }^{10}$.

Após nove meses de estoque, não houve diferença estatística entre os métodos ágar Dixon e ágar Dixon acrescido de glicerol, que apresentaram-se como os melhores $(p<0,05)$ para manutenção da viabilidade dos microrganismos estocados. Contudo, houve drástica redução na recuperação das cepas estocadas em ágar Dixon acrescido de DMSO. Portanto, o uso deste crioprotetor deve ser contra-indicado na estocagem de M. pachydermatis por mais de seis meses.
No tocante à preservação da atividade da urease após seis meses de estocagem, não se observaram diferenças estatísticas com nenhum dos métodos empregados. Por outro lado, aos nove meses os resultados mais promissores $(p<0,05)$ foram observados em ágar Dixon e ágar Dixon acrescido de glicerol. Cabe ressaltar que 0 teste de urease foi grandemente afetado pelo período de estocagem e, talvez, pelas temperaturas de manutenção das cepas.

Os resultados desta pesquisa evidenciaram que os métodos que apresentaram melhor desempenho na manutenção da viabilidade das cepas, aos seis e nove meses, e positividade na prova de urease, aos nove meses, foram o ágar Dixon e ágar Dixon acrescido de glicerol. Portanto, conclui-se que para manutenção e recuperação de cepas de M pachydermatis, um desses dois métodos pode ser utilizado.

\section{REFERÊNCIA BIBLIOGRÁFICA}

1. Bond R, Antony RM. Characterization of markedly lipid-dependent Malassezia pachydermatis isolates from healthy dogs. Journal of Applied Bacteriology 78:537-542, 1995.

2. Borba, CM, Rodrigues KF. Viability and sporulating capability of Coelomycetes preserved under a range of different storage regimes. Revista Iberoamericana de Micología 17:142-145, 2000.

3. Breirová E, Kocková-Kratochvílová A, Delgado R. Storage of Candida albicans, C. tropicalis and related species in liquid nitrogen. Folia Microbiologica 32:426-430, 1987.

4. Breirová E, Kocková-Kratochvílová A, Sajbidor J, Ladzianska K. Malassezia pachydermatis: Properties and storage. Mycoses 34: 349-352,1992.

5. Brilhante RSN. Estudo das dermatofitoses canina e felina: Aspectos epidemiológicos e comportamento do Microsporum canis frente a diferentes métodos de estocagem. Dissertação de Mestrado, Universidade Estadual do Ceará, Fortaleza, CE, 2002.

6. Bueno L, Gallardo R. Preservación de hongos filamentosos en água destilada estéril. Revista Iberoamericana de Micología 15:166-168, 1998.

7. Caprilles CH, Mata S, Middelveen M. Preservation of fungi in water (Castellani) : 20 years. Mycopathologia 106:73-79, 1989.

8. Castellani A. Viability of some pathogenic fungi in distilled water. Journal of Tropical Medicine and Hygiene 42: 225-226, 1939.

9. Coutinho SDA. Malasseziose: a necessidade de se pesquisar as espécies lipodependentes em medicina veterinária. Revista Brasileira de Medicina Veterinária 1:70-73, 2003.

10. Crespo MJ, Abarca ML, Cabañes FJ. Evaluation of different preservation and storage methods for Malassezia spp. Journal of Clinical Microbiology 38: 3872-3875, 2000.

11. Crespo MJ, Abarca ML, Cabañes FJ. Occurrence of Malassezia spp in the external ear canals of dogs and cats with and without otitis externa. Medical Mycology 40:115-121, 2002.

12. Duarte ER, Lachance M, Hamdan JS. Identification of atypical strains of Malassezia spp from cattle and dog. Canadian Journal of Microbiology 48:749-752, 2002

13. Dworecka-Kaszak B, Toka FN. Comparison of different methods of maintenance of Malassezia pachydermatis (Pityrosporum pachydermatis) strains. Acta Microbiologica Polonica 45:103-105, 1996.

14. Fisher RA. The logic of inductive inference. Journal of the Royal Statistical Society 98: 34-54, 1935.

15. Guého E, Midgley G, Guillot J. The genus Malassezia with description of four new species. Antonie Van Leeuwenhoek 69:337-355, 1996.

16. GuillotJ, Bond R. Malassezia pachydermatis: a review. Medical Mycology 37: 295-306, 1999. 
17. Huang HP, Little CJL, Fixter LM. Effects of fatty acids on the growth of Malassezia pachydermatis and their relevance to canine otitis externa. Research in Veterinary Science 55:119-123, 1993.

18. Kreger-van Rij NW. The yeasts: a taxonomic study. 3.ed. Elsevier Science Publishers, Amsterdam, 1994.

19. Larocco M, Dorenbaum A, Robinson A, Pickering LK. Recovery of Malassezia pachydermatis from eight infants in a neonatal intensive care nursery: clinical and laboratory features. Journal of Pediatric Infection Diseases 7:398-401, 1988.

20. Leite CAL. Abreu VLV. Costa G.M. Freqüência de Malassezia pachydermatis em otite externa de cães. Arquivo Brasileiro de Medicina Veterinária e Zootecnia 55:102-104, 2003
21. Lima, RF, Borba, CM. Viability, morphological characteristics and dimorphic ability of fungi preserved by different methods. Revista Iberoamericana de Micología 18:191-196, 2001.

22. Machado MLS, Appelt CE., Ferreiro L, Guillot J. Otites e dermatites por Malassezia spp em cães e gatos. Clínica Veterinária 44:27-34, 2003.

23. Passarell $\mathrm{L}, \mathrm{Mc}$ Ginnis MR. Viability of fungal culture maintained at $-70^{\circ} \mathrm{C}$. Journal of Clinical Microbiology 30:1000-1004, 1992.

24. Rodrigues EG, Lírio VS, Lacaz CS. Preservação de fungos e actinomicetos de interesse médico em água destilada. Revista do Instituto de Medicina Tropical 34:159-165, 1992.

25. Sidrim JJC, Moreira JLB. Fundamentos Clínicos e Laboratoriais da Micologia Médica. Editora Guanabara Koogan, Rio de Janeiro, 1999. 